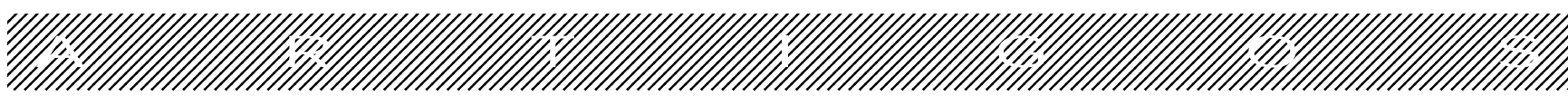

\title{
Husserl e a Psicologia
}

\author{
Rafael Raffaelli \\ Universidade Federal de Santa Catarina
}

\begin{abstract}
Resumo
O objetivo deste estudo é esclarecer a relação entre a fenomenologia de Husserl e a psicologia. Embora Husserl traçasse um paralelo entre fenomenologia e psicologia, ele não supunha uma identidade entre essas duas disciplinas. A psicologia é uma ciência de fatos e a fenomenologia é a base para a compreensão do sentido desses fatos. A psicologia pode ser considerada uma ciência autônoma que estuda a psique através do comportamento. Mas a interpretação da significação subjacente ao comportamento só pode ser realizada pela psicologia eidética. A psicologia eidética, fundada na fenomenologia, é que conduziria a depuração do naturalismo que impregna a psicologia empírica. Segundo Husserl, a psicologia não necessita dos conselhos metodológicos das ciências da natureza e deve buscar seu próprio caminho para compreender o sentido do ato humano. Assim, o que a psicologia precisa é de um "plus ultra" conectando a investigação psicológica com o transcendental.
\end{abstract}

Palavras-chave: fenomenologia; psicologia; epistemologia; ontologia

\begin{abstract}
Husserl and Psychology. The aim of this study is to clarify the relation between Husserl's phenomenology and psychology. Although Husserl pointed out a similarity between phenomenology and psychology, he did not suppose an identity between the two disciplines. Psychology is a science of facts and phenomenology is the basis to understand the sense of those facts. Psychology may be considered as an autonomous science that studies the psyche through the behavior. But the interpretation of the signification that underlies the behavior can only be made by eidetic psychology. Eidetic psychology, based on the phenomenology, would conduct the depuration of the naturalism that impregnates empirical psychology. According to Husserl, psychology does not need methodological advices from the sciences of nature and must find his own way to understand the sense of the human act. Thus, what psychology needs is a "plus ultra" connecting the psychological investigation with the transcendental.
\end{abstract}

Key words: phenomenology; psychology; epistemology; ontology

$\mathrm{E}$ dmond Husserl (1859-1938), filósofo alemão de origem judaica, nascido em Prosznitz, Morávia - nos domínios do Império Austro-húngaro - teve uma formação acadêmica em matemática na Universidade de Berlim e doutorou-se nessa disciplina em 1882, em Viena. Na mesma cidade, a partir de 1884, passou a estudar com Franz Brentano (1838-1917), que o influenciou a dedicar-se à filosofia. Em 1887 defendeu tese de livre-docência na Universidade de Halle denominada Sobre o conceito de número, mas sua primeira obra só seria publicada em 1891, constituindo-se no tomo inicial da Filosofia da Aritmética. Entre 1900 e 1901 publicou
As investigações lógicas, dividida em dois volumes, publicação esta originada de seu curso Prolegômenos à Lógica Pura, de 1896. Em 1911, redigiu um artigo para a revista Logus intitulado A Filosofia como ciência rigorosa, que lhe granjeou notoriedade e, em 1913, veio à luz o primeiro tomo da obra Idéias relativas a uma fenomenologia pura e uma filosofia fenomenológica, na qual estabeleceu o seu programa filosófico. Em 1916 passou a lecionar na Universidade de Friburgo, onde Martin Heidegger tornou-se seu assistente de 1919 a 1923. Seu livro seguinte, Lógica Formal e Lógica Transcendental, é impresso em 1919. Profere, no mesmo ano, 
conferências em Paris, que foram publicadas posteriormente, em 1931, com o nome de Meditações cartesianas. O texto $A$ consciência íntima do tempo, redigido em 1905, é publicado em 1928 no Anuário de investigação fenomenológica (Jahrbuch), com edição de Heidegger. Em 1936, a primeira e a segunda parte de A crise das ciências européias e a fenomenologia transcendental foram publicadas em Belgrado - devido à proibição de seus trabalhos na Alemanha hitlerista -, texto que só seria publicado na íntegra em 1954. Morreu em abril de 1938, aos 79 anos de idade, deixando cerca de 40.000 páginas taquigrafadas, fruto de seu ensino e de sua pesquisa filosófica. Excertos desses escritos foram reunidos num volume denominado Experiência e julgamento, investigações sobre a genealogia da Lógica, que foi publicado em Praga no ano seguinte ao seu falecimento. O restante desse material continua ainda inédito e está depositado, em sua maior parte, nos Arquivos Husserl da Universidade de Louvain (Bélgica) e também em Colônia (Alemanha) e na Escola Normal Superior em Paris (apud English, 2001).

Frente à vastíssima obra de Husserl, e reconhecendo as limitações do presente ensaio, nos ateremos ao texto das Idéias relativas a uma fenomenologia pura e uma filosofia fenomenológica e de A crise das ciências européias e a fenomenologia transcendental, em que são desenvolvidas algumas das perspectivas referentes à psicologia. Utilizaremos também os comentários de Merleau-Ponty e outros autores, em especial a obra Ciências do homem e fenomenologia.

Buscamos responder três questões: Como Husserl avaliava a psicologia enquanto ciência? Qual o papel da fenomenologia na constituição da psicologia? A idéia de uma psicologia como ciência universal é válida frente à ciência contemporânea?

Esclarecendo brevemente a terminologia empregada, denominaremos psicologia fenomenológica ou eidética àquela que trabalha em conformidade ao aporte husserliano, segundo o programa filosófico fenomenológico e tendo como método a redução fenomenológica ou eidética. Psicologias de inspiração fenomenológica são aquelas que partem de uma concepção de mundo fundada na fenomenologia, mas empregam outras metodologias de trabalho ou seguem caminhos teóricos diferenciados. O termo psicologia faz referência ao conjunto das teorias - de viés naturalista - advindas da pesquisa comportamental empregando metodologia experimental ou estatística, incluindo a psicofísica. Finalmente, psicologia como ciência universal refere-se à totalidade do corpus da disciplina, nas modalidades naturalista-experimental e interpretativa.

A filosofia de Husserl propunha um paralelismo entre a psicologia e a fenomenologia, pois toda a pesquisa psicológica empírica afirma uma verdade fenomenológica ou eidética, quer dizer, essencial (eidos significando idéia ou essência em oposição aos fenômenos sensíveis transitórios ou aistheta). Distancia-se, assim, de uma psicologia puramente reflexiva, de prisma filosófico.

Entretanto, Husserl nunca supôs uma identidade entre as duas disciplinas: "A fenomenologia pura (...) não é psicologia” (Husserl, 1913/1986, p. 8). Para ele a psicologia se constitui numa ciência empírica, quer dizer, baseada na experiência.

\begin{abstract}
Isto implica, dada a significação usual da palavra experiência, duas coisas: (1) a psicologia é uma ciência de fatos, de matters of fact no sentido de Hume; (2) a psicologia é uma ciência de realidades. Os fenômenos de que trata a fenomenologia psicológica são eventos reais, que enquanto tais, quando têm existência real, se inserem com os sujeitos reais a que pertencem dentro da ordem do mundo uno do espaço e do tempo ou da omnitudo realitatis. (Husserl, 1913/1986, p. 10) ${ }^{1}$
\end{abstract}

A busca pela verdade do fenômeno indica que tanto a psicologia do comportamento como a psicologia eidética trabalham com o mesmo sujeito e que a realidade humana é onde se insere o transcendental, aquilo que supera a realidade imediata e lhe confere sentido. Desse modo, o estudo experimental já nos revelaria a essência de forma velada, sendo a tarefa da psicologia compreendê-la, desvendá-la. Mas para tanto, é preciso superar os preconceitos naturalistas que embasam o experimentalismo.

Dentre os sistemas psicológicos, a Gestalttheorie foi a escola que mais se aproximou dos ideais de Husserl. Formada por antigos alunos do filósofo, consagrou-se ao estudo experimental da percepção, buscando relacionar o domínio da experimentação com a interpretação fenomenológica. A própria noção de forma mantém um parentesco com a noção de essência em Husserl. (cf. Dartigues, 1981, pp. 48-49).

Contudo, Husserl fazia restrições aos sistemas psicológicos - até mesmo à teoria da Gestalt - e essas objeções se referiam principalmente à desconsideração da consciência como a origem dos fenômenos psíquicos (cf. Merleau-Ponty, 1951/1973, p. 51).

Costuma-se dizer que Husserl não se interessa pela psicologia. A verdade é que ele mantém suas antigas críticas ao Psicologismo e insiste sempre na redução em virtude da qual se passa da atitude natural, que é a da psicologia, como a de todas as ciências positivas, à atitude transcendental, que é a da filosofia fenomenológica. (...) Mas é preciso insistir no fato de que tais análises não visam absolutamente a substituir a psicologia. A renovação da qual se trata não é uma invasão. Tratase de renovar a psicologia em seu próprio terreno, de verificar seus métodos próprios através de análises que fixem o sentido, sempre impreciso, das essências fundamentais, tais como as de representação, recordação, etc. (Merleau-Ponty, 1934/1990, pp. 21-22)

A psicologia pode ser considerada uma ciência autônoma na medida em que pesquisa o comportamento, contudo a significação subjacente ao comportamento demanda uma interpretação. Essa interpretação do sentido é que Husserl denominava a tarefa da psicologia eidética, isto é, da reflexão fenomenológica sobre os fundamentos naturalistas sobre os quais se apóia a psicologia empírica. Dessa forma, "a fenomenologia constitui o essencial fundamento eidético da psicologia e das ciências do espírito" (Husserl, 1913/ 1986, p. 47). 
Para ele, a psicologia é verdadeiramente uma ciência e seu objetivo é descrever a relação homem/mundo em termos de condutas.

A psicologia, para Husserl, continua sendo como a física ou a astronomia uma ciência da atitude natural, isto é, uma ciência que implica em um realismo espontâneo. Ao contrário, a fenomenologia começa quando "colocamos fora de jogo a posição geral de existência que pertence à essência da atitude natural”. (...) A psicologia é um empirismo que procura ainda seus princípios eidéticos. Husserl, a quem se reprovou freqüentemente, de forma errônea, uma hostilidade de princípio contra essa disciplina, se propõe ao contrário a prestar um serviço a ela: não nega a existência de uma psicologia de experiência; mas pensa que, para atender ao mais urgente, o psicólogo deve constituir antes de tudo uma psicologia eidética. (Sartre, 1980, pp. 104-107)

Husserl rejeita a distinção entre ciência descritiva e ciência explicativa, tal como suposta por Brentano e Dilthey, pois ao realizar a crítica das concepções naturalistas da psicologia, enfatizou o conceito de experiência, fruto da vivência humana no mundo. No tocante à interpretação científica, considerou que a aporia entre ciências descritivas e explicativas não procede, dado desconsiderar o fundamento ôntico que as unifica (Husserl, 1935/1976, p. 250). Para ele, a redução fenomenológica ultrapassa o naturalismo e a natureza é encarada como noema, o "sentido puro dos atos que compõem a atitude natural" (Husserl, citado por Merleau-Ponty, 1960/ 1991, p. 178).

A consciência é sempre consciência de algo e por isso "não há noese sem noema, cogito sem cogitatum, mas também não há amo sem amatum, etc.; em resumo, encontro-me entrelaçado com o mundo" (Lyotard, 1986, p. 55).

Por isso, a empiria psicofísica - embora legítima, ou até mesmo inevitável - não pode ser a base de uma psicologia autêntica, capaz de se referir ao ser próprio do psiquismo. No psíquico, no seu senso próprio, "não há natureza, não há um em-si pensável no sentido natural, nem em-si causal espaçotemporal, idealizável e matematizável, nem leis do gênero das leis da natureza" (Husserl, 1935/1976, p. 250).

A idéia de uma psicologia exata, análoga à física, é um contra-senso para Husserl. Para ele, a psicologia não necessita dos conselhos metodológicos das ciências da natureza, pois a psique possui essencialidade própria, não comparável àquela do mundo natural. Mas com isso não visa separar a experiência do espírito da experiência do corpo - como numa reedição da aporia cartesiana - ao contrário, visa incluir no próprio psíquico a noção de corpo (Husserl, 1935/1976, pp. 253-254).

Porém para desvendar essa relação entre psique e soma o trabalho de interpretação é necessário, pois o homem não se constitui apenas em partícipe do mundo, mas é o ponto de origem da reflexão. Essa reflexão surge de uma intencionalidade do ser humano em relação aos seus semelhantes e às coisas do mundo, em que opera o sentido que unifica as subjetividades, transformando-as em realidades compartilhadas, cujo desvelamento é a tarefa da psicologia.
Dessa forma, a questão do ser - e da condição humana no contexto sociohistórico - é o que permite complementar a visão empírica da psicologia descritiva.

A consciência transcendental só se realiza na existência humana entendida como psiquismo, o que nos leva à estrutura do comportamento. A consciência impessoal que dirige as relações entre os homens e sobre a qual se erige a sociedade é a estrutura do comportamento observável. Para além desse limite, o comportamento exprime um modo de existência único, cujo significado escapa à causalidade imediata (MerleauPonty, 1945/1975, p. 253).

Husserl propunha que a filosofia deveria ser a ciência do omnitemporal, quer dizer, ciência daquilo que tem validade em todos os tempos, buscando escapar ao psicologismo e o logicismo. Mas o pensamento não existe desencarnado, pois produto de uma individualidade, e devido a isso a necessidade do recurso ao fato para se fundar uma subjetividade transcendental, que se define como intersubjetividade, para determinar "o sentido das relações reais entre a pessoa e as outras realidades" (Husserl, 1935/1976, p. 265).

Como atesta Merleau-Ponty:

Compreendo afinal o que quer dizer a enigmática proposição de Husserl: "a subjetividade transcendental é intersubjetividade". Na medida em que o que digo tem sentido, sou para mim mesmo, quando falo, um outro "outro", e, na medida em que compreendo, já não sei quem fala e quem ouve. (Merleau-Ponty, 1960/1991, pp.103-104)

Desse modo, o eu psíquico só tem sentido quando envolvido numa experiência vital, num campo fenomenológico.

\footnotetext{
Há que se convencer de que todo o psíquico no sentido da psicologia, as personalidades psíquicas, as propriedades, vivências ou estados psíquicos, são unidades empíricas; são, pois, como as realidades em sentido estrito de toda classe e grau, meras unidades de "constituição" intencional - existentes verdadeiramente em seu sentido; suscetíveis de serem intuídas, experimentadas, determinadas cientificamente sobre a base da experiência - e sem dúvida, "meramente intencionais" e por ente meramente "relativas". Tomá-las por existentes num sentido absoluto é, pois, um contra-senso. (Husserl, 1913/1986, pp.128-129)
}

A psicologia partiria de uma visão ingênua do mundo, sem possuir o pressentimento de um plus ultra, isto é, de um novo horizonte temático que faculte a compreensão do transcendental no fluxo do ser e na vida psíquica. Mas essa compreensão não é de feitio idealista, de modo introspectivo, pois o que interessa não é a afirmação dúbia de um $\mathrm{Eu}$ - que nada é em si - mas a intersubjetividade que surge do ato concreto no mundo vivido. Assim, Husserl afirma a racionalidade através da experiência, do fato psicológico, em que a verdade surge a partir daquilo que não é contingente por meio da intuição das essências (Wesenschau). E o ponto de partida dessa reflexão é sempre o retorno ao mundo vivido (Lebenswelt), o primeiro e indispensável procedimento metodológico. 
Husserl nada tem contra uma psicologia científica. Apenas acredita que a existência e o desenvolvimento de uma tal psicologia colocam problemas filosóficos, cuja solução interessa à própria psicologia, já que ela deve vencer os impasses. $\mathrm{O}$ problema é o seguinte: considerando o estado do saber, no momento que Husserl escrevia, parecia haver um conflito entre as exigências de uma filosofia, exigências de uma interioridade racional pura, e as exigências de uma psicologia considerada como ciência da determinação exterior das condutas do homem. (...) A visão das essências baseia-se simplesmente na possibilidade de distinguir, em nossa experiência, o fato de vivê-la e aquilo que através dela vivemos. (MerleauPonty, 1951/1973, pp. 27-28)

Para Husserl, então, o objetivo final de uma ciência psicológica seria determinar as estruturas inteligíveis que vão além do meramente observável, do empírico. Nesse sentido, a psicologia é ciência do homem frente ao mundo, preocupada em compreender os padrões de comportamento eliciados por determinadas situações.

A psicologia devia fracassar, pois ela não pôde realizar sua tarefa, aquela de uma pesquisa da subjetividade na sua plenitude concreta, que por uma meditação radical, inteiramente livre de pré-julgamentos, teria necessariamente aberto as dimensões transcendental-subjetivas. (Husserl, 1935/1976, p. 239)

Porque a compreensão do fluxo do mundo vivido não figura como o ponto de início da psicologia?, questionava Husserl. Pois sabemos que qualquer ciência natural - como a psicologia aspira - não parte da natureza mesma como conhecida pela intuição, mas do corpo teórico que a substitui hipoteticamente. O dualismo cartesiano que separou mens e corpus implicou, também, a naturalização do ser psíquico (Husserl, 1935/1976, p. 249). Mas sem uma ontologia que explicite essa relação homem-mundo a psicologia torna-se psicologismo, partilhando das convicções do senso comum sobre o ser. Dessa forma, pode-se dizer que se o conhecimento dos fatos é o trabalho da psicologia empírica, então a reflexão sobre a significação dos conceitos psicológicos é a tarefa da fenomenologia ou psicologia eidética e o cerne de seu método é a "redução fenomenológico-psicológica" (Husserl, 1935/1976, p. 265).

Por conseguinte, a fim de compreendermos verdadeiramente aquilo que sabemos a respeito do homem, é mister combinar a indução com o conhecimento reflexivo que de nós mesmos podemos obter enquanto sujeitos conscientes. (...) A autonomia da psicologia se manifesta na sua tarefa de investigar os fatos e as relações de fato; mas a significação última destes fatos e destas relações só pode ser fornecida por eidética fenomenológica, na qual distinguimos o sentido ou a essência da percepção, da imagem e da consciência. (Merleau-Ponty, 1951/1973, pp. 33-34)

A investigação sobre o estatuto da percepção conduzida por Merleau-Ponty (1964; 1945/1979) - seu mais brilhante continuador - demonstra a intensa influência da filosofia husserliana sobre a psicologia moderna, que permanece viva como um legado para os dias de hoje, pois as idéias de Husserl continuam sendo um instrumento de crítica contra o empirismo ingênuo ou a atitude natural dos psicólogos, isenta de reflexão.

Pois, como postulava Husserl, a psicologia como ciência universal poderia ter outro tema que o subjetivo em seu conjunto? A análise filosófica - que não esteja cega pelo préjulgamento naturalista - não ensina que todo o subjetivo pertence a uma totalidade indivisível e que não há sentido na separação entre experiência externa e vivência interior? (Husserl, 1935/1976, p. 248).

Frente a esse questionamento, constatamos que na ciência psicológica atual persiste o descompasso, que Husserl criticava na psicologia do século XIX, entre o campo da psicofísica e da pesquisa comportamental - enfatizando o controle e a experimentação e produzindo "dados" - e o campo da psicologia filosófica e da psicologia clínica, interessadas no ser e na emoção, gerando "abstrações". A continuidade do antagonismo entre data e abstracta (Husserl, 1935/ 1976, p. 258) demonstra que o ideal husserliano da unificação da psicologia enquanto ciência da experiência ainda não produziu efeitos notáveis. Nesse sentido, um sintoma desse conflito irresoluto é a desvinculação entre psicanálise e psicologia, como se tratassem de disciplinas antitéticas.

Ao invés de uma defesa da psicologia filosófica em detrimento da psicologia experimental - como a fenomenologia tem sido às vezes erroneamente encarada - o ideal de Husserl era o desenvolvimento de uma psicologia como ciência universal, através da noção de experiência intencional, para além das visões dicotômicas que persistem em cindir a disciplina em campos opostos e excludentes.

Tal tarefa, embora de relevância filosófica, se mostra praticamente inexequiível não só devido às incongruências epistemológicas irredutíveis, mas também frente à, cada vez maior, especialização do conhecimento, fato que afeta as ciências como um todo e não apenas a psicologia. A situação atual da ciência e da universidade é descrita por Morin (1977/ 1997, p. 16) como uma escola do luto, na qual o saber existe não para ser abstraído e articulado com outros saberes para gerar uma visão de mundo, mas para ser acumulado anonimamente, sem que jamais se obtenha uma idéia do conjunto.

Assim, a constatação da inviabilidade do ideal de Husserl em relação à psicologia como ciência universal não diria também da inviabilidade da articulação do conhecimento científico como um todo, como uma mathesis universalis? (Foucault, 1966/1977, p. 449). Isso sugeriria, talvez, que a alternativa viável seria a abordagem transdisciplinar, na tentativa de se obter junções entre os diversos saberes, que recoloquem as questões fundamentais para a fenomenologia, para a psicologia e para a ciência em geral: "Que é o homem, que é o mundo, que é o homem no mundo?” (Morin, 1977/1997, p.16).

\section{Referências}

Dartigues, A. (1981). La fenomenología. Barcelona: Herder.

English, J. (2001). Husserl. In D. Huisman (Org.), Dicionário dos filósofos (pp. 523-532). São Paulo: Martins Fontes. (Edição original 1984) 
Foucault, M. (1977). As palavras e as coisas: uma arqueologia das ciências humanas. (A. R. Rosa, Trad.). Lisboa: Portugália. (Texto original publicado em 1966)

Husserl, E. (1976). La crise des sciences européennes et la phénoménologie transcendentale. Paris: Gallimard. (Texto original redigido em 1935 e publicado em 1954)

Husserl, E. (1986). Ideas relativas a una fenomenologia pura y una filosofia fenomenológica. México: Fondo de Cultura Econômica. (Texto original publicado em 1913)

Lyotard, J.-F. (1986). A fenomenologia (A. Rodrigues, Trad.). Lisboa: Edições 70. (Texto original publicado em 1954)

Merleau-Ponty, M. (1964). Le visible et le invisible. Paris: Gallimard.

Merleau-Ponty, M. (1973). Ciências do homem e fenomenologia (S. T. Muchail, Trad.). São Paulo: Saraiva. (Texto original redigido em 1950-1951)
Merleau-Ponty, M. (1975). A estrutura do comportamento (J. A. Corrêa, Trad.). Belo Horizonte: Interlivros. (Texto original publicado em 1945)

Merleau-Ponty, M. (1979). Phénoménologie de la perception. Paris: Gallimard. (Texto original publicado em 1945)

Merleau-Ponty, M. (1990). O primado da percepção e suas conseqüências filosóficas (C. M. Cesar, Trad.). Campinas: Papirus. (Texto original redigido em 1934 e publicado em 1989)

Merleau-Ponty, M. (1991). Signos (M. E. G. G. Pereira, Trad.). São Paulo: Martins Fontes. (Texto original publicado em 1960)

Morin, E. (1997). O método. 1. A natureza da natureza (M. G. Bragança, Trad.). Mira-Sintra: Europa-América. (Texto original publicado em 1977)

Sartre, J.-P. (1980). A imaginação (L. R. S. Fortes, Trad.). São Paulo: Difel. (Texto original publicado em 1940)

1 As citações de Husserl (1935/1976; 1913/1986) utilizadas foram traduzidas pelo próprio autor deste ensaio.

Rafael Raffaelli, doutor em Psicologia Clínica pela Pontifícia Universidade Católica de São Paulo, é professor titular no departamento de Psicologia da Universidade Federal de Santa Catarina. Endereço para correspondência: Rua Aracuã, 351 (Pantanal); Florianópolis, SC; CEP 88040-310. Fone: (48) 233-6989. Fax: (48) 2333247. E-mail: raraffa@aol.com 